\title{
Variable Structure Back-Stepping Control of Two-stage Three Phase Grid Connected PV Inverter
}

\author{
Nasim Ullah" ${ }^{1 *}$ Ahmad Aziz Al Ahmadi ${ }^{1}$ \\ ${ }^{1}$ Department of Electrical Engineering, College of Engineering, Taif University, Al-Huwayah, 21974 Taif, P.O.B. 888, Saudi Arabia \\ * Corresponding author, e-mail: nasimullah@tu.edu.sa
}

Received: 11 December 2019, Accepted: 07 February 2020, Published online: 08 July 2020

\begin{abstract}
This work presents a detailed analysis of a three phase grid tied photovoltaic inverter with variable structure back-stepping control approach. A nonlinear model of the system is derived and presented in rotational frame using the direct quadrature zero transformation (DQ). For the derivation of active and reactive power loops of the inverter, nonlinear back stepping approach is used. Moreover, sliding mode control method is used to derive the inner current loops while for the outer loop a virtual controller is derived using the Lyapunov function. The control loops are implemented in MATLAB/Simulink environment. To test the controller performance, active power variation, DC link voltage variation and reactive power variations are inflicted. The obtained results under the proposed control scheme are compared with boundary layer design based sliding mode controller. From the comparative analysis it is concluded that the proposed controller exhibit superior and robust performance under all test conditions.
\end{abstract}

\section{Keywords}

voltage source inverter, sliding mode controller, backstepping, renewable energy, solar photovoltaic systems

\section{Introduction}

Photovoltaic energy is the key power source with distinctive advantages such that it is pollution free and easy in installation. A study conducted by National Renewable Energy Laboratory (NREL) USA in collaboration with the USAID reported that Pakistan has a huge potential of about 2900 giga watts from the solar energy resources [1]. According to another review [2], the annual installed capacity of solar power around the globe is around $400 \mathrm{GW}$. In the last five years, an annual growth rate of $60 \%$ has been reported in the PV energy conversion systems [3].

As per the standard grid codes, power quality is an important factor that needs to be taken care of in the integration of the inverter fed distributed generation systems. With the advancement of the power semiconductor technology, the grid integrating topologies are becoming smarter and thus the overall cost is also reduced with the omission of bulky components. In grid tied inverter (GTI), the power produced by PV panels is directly fed to the transmission line through grid for distribution. Therefore, the use of storage devices like batteries are not required [4-6]. For photovoltaic applications, the utilization of the transformerless inverters has been widely reported in the existence literature $[7,8]$. Recently by placing various industry standards, the transformerless inverters have been developed in the range of kilowatt $(\mathrm{kW})$.

However, the exclusion of transformer from power system produces leakage current $[9,10]$. In order to analyze the leakage current in the grid tied inverters, several metrologies have been reported in the literature such as minimization of leakage current using switching logic [11], common mode filter implementation method [12], leakage current minimization using modulation method [13] A comprehensive review on different transformerless inverters has been reported in $[14,15]$.

Apart from the leakage current, the closed loop control system is another important area of research. In the existent literature, several control methods have been reported for grid tied inverters. Classical control methods such as proportional integral (PI) and optimized PI controller have been proposed in $[16,17]$. Classical control methods are easy design and suitable from the implementation point of view, however these methods are not robust against the system uncertainties and nonlinear disturbances. Apart from classical control methods, intelligent control methods such 
as fuzzy and artificial neural network based hybrid control schemes have been reported in [18-20]. Fuzzy and neural network controllers are effective in a situation if the dynamic model of the system is not known. However in case of grid tied inverter, the nominal dynamic model of the system is usually known. So the fuzzy and neural controllers are hard to tune and it also takes huge computational resources when it is implemented on the digital processors.

Model predictive controllers are easily implementable and suitable for many practical systems. Several variants of model predictive controllers have been reported in the literature for grid tied inverters [21-23]. Although the model predictive controllers are very effective, however the dynamics of the grid tied converters are coupled so along with model predictive controllers, usually PI controllers are used in the inner or outer coupled loop of active power and DC link voltage stabilization loop. Thus the addition of PI controllers reduces the overall effectiveness of the model predictive controllers.

Sliding mode control system is frequently reported in the literature and it is applied to both linear and nonlinear systems. Sliding mode control system (SMC) is embedded as a backstepping controller using Lyapunov function method [24].

Several control methods based on SMC are reported in literature such as integer and fractional order controllers for power converters [25], SMC based backstepping control method for grid tied parallel inverters [26], and classical SMC based grid tied inverter controllers in [27, 28].

Based on the above cited literature, this paper is focused on the following.

- Analyze system model in d-q frame

- Formulate a virtual controller for DC link voltage stabilization

- Formulate the active and reactive current/power control loops using backstepping and sliding mode approach.

- Compare the performance of the grid tied inverter under the action of the proposed control and a saturation function based SMC control.

The rest of the paper is organized as following: The system model is is presented in Section 2. In Section 3 the control system is derived. Section 4 presents the results and discussions. Finally conclusion is made.

\section{Description and modeling of grid-connected PV systems}

The block diagram and Simulink model of a grid tied three phase inverter are shown in Figs. 1 and 2. As shown in

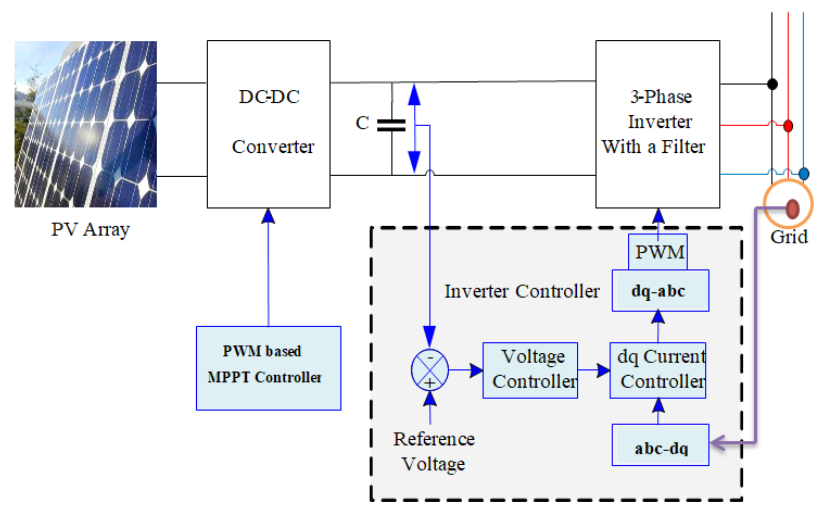

Fig. 1 Block diagram of the system

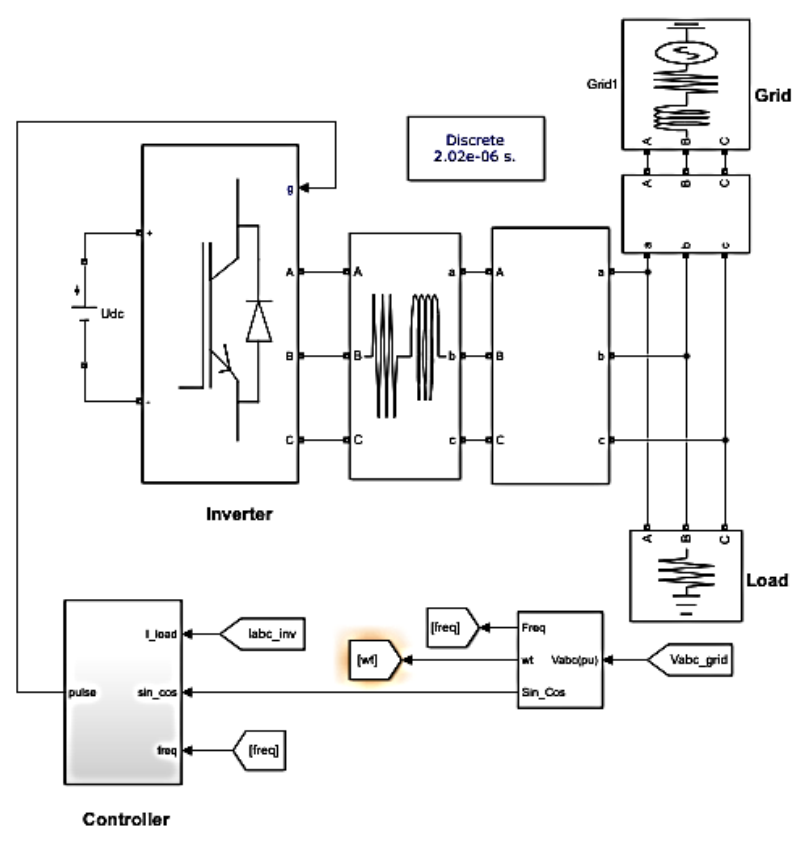

Fig. 2 Simulink model

Figs. 1 and 2, the controller is realized in $d$ - $q$ reference frame. Thus the measured three phase load currents are first converted to $d-q$ reference frame. The converted $d$ and $q$ axis currents are utilized as feedback in the control law simulations. The generated control signals from $d$ and $q$ axis current control loops are converted back to three phase system using d-q-abc transformation.

In $d-q$ reference frame, a three phase grid tied inverter is represented by the following mathematical equations as shown in Eq. (1) [1].

$$
\begin{aligned}
& \dot{i}_{d}=\omega i_{q}+\frac{1}{L} v_{c} u_{d}-\frac{1}{L} v_{g d}, \\
& \dot{i}_{q}=-\omega i_{d}+\frac{1}{L} v_{c} u_{q}, \\
& \dot{v}_{c}=\frac{1}{C v_{c}}\left(p_{i n}-\frac{3}{2} v_{g d} i_{d}\right) .
\end{aligned}
$$

From Eq. (1), $u_{d}$ and $u_{q}$ represent $d$ and $q$ axis voltages, $i_{d}$ and $i_{q}$ show the $d$ and $q$ axis currents, $v_{c}$ is the DC bus 
voltage, $C$ represents DC bus capacitance, $L$ is the inductance, $w$ is the angular frequency, $p_{\text {in }}$ represents the input power and $v_{g d}$ is the grid voltage.

\section{Active, reactive currents and DC link voltage stabilization controllers}

In Section 3 the detailed formulation of active, reactive and DC link voltage stabilization controllers is presenteed. The controllers are derived based on the $d$ - $q$ model given in Eq. (1).

\subsection{Virtual controller for DC bus voltage stabilization}

In Subsection 3.1, a virtual controller is formulated that is primarily used for DC bus voltage stabilization. This virtual controller also serves as a reference for the $d$ axis current control scheme which will be derived in Subsection 3.2. Define the error between the reference command of DC bus voltage and the measured DC bus voltage as following:

$e_{v}=v_{c}-v_{c, r e f}$.

By taking the first derivative of Eq. (2), one obtains the following relation:

$\dot{e}_{v}=\dot{v}_{c}-\dot{v}_{c, r e f}$.

A proportional integral (PI) type sliding manifold and its first derivative is shown in Eq. (4).

$S_{v}=c_{5} e_{v}+c_{6} \int e_{v}$

$\dot{S}_{v}=c_{5} \dot{e}_{v}+c_{6} e_{v}$.

Substituting the dynamics of the DC bus voltage from Eq. (1) into Eq. (3), 4 yield the following expression:

$\dot{S}_{v}=c_{5}\left[\frac{1}{C v_{c}}\left(p_{i n}-\frac{3}{2} v_{g d} i_{d}\right)-\dot{v}_{c, r e f}\right]+c_{6} e_{v}$.

By letting $\dot{S}_{d}=-k_{1} \operatorname{sgn}\left(S_{d}\right)$, the virtual control law is formulated in the following form:

$i_{d, r e f}=-\frac{2}{3 * v_{g d}}\left[\begin{array}{l}\left.\left(C v_{c}\left[-\frac{k_{3}}{c_{5}} \operatorname{sgn}\left(S_{v}\right)-\frac{c_{6}}{c_{5}} e_{v}+\dot{v}_{c, r e f}\right]\right)\right] . \\ -p_{i n}\end{array}\right]$.

The virtual controller $i_{d, r e f}$ serves as a reference command for the $d$ axis controller scheme.

\subsection{Direct-axis current controller}

As discussed in the previous Subsection 3.1, the virtual controller $i_{d, r e}$ serves as the reference command for the $\mathrm{d}$ axis controller. Tracking error for $\mathrm{d}$ axis current is defined as following: $e_{d}=i_{d}-i_{d, r e f}$.

The first derivative of Eq. (7) is expressed as following:

$\dot{e}_{d}=\dot{i}_{d}-\dot{i}_{d, r e f}$.

A proportional integral (PI) type sliding manifold and its first derivative is shown in Eq. (9):

$S_{d}=c_{1} e_{d}+c_{2} \int e_{d}$
$\dot{S}_{d}=c_{1} \dot{e}_{d}+c_{2} e_{d}$.

Substituting the dynamics of the $d$ axis current from Eq. (1) into Eq. (8) and Eq. (9) yields the following expression:

$\dot{S}_{d}=c_{1}\left(\omega i_{q}+\frac{1}{L} v_{c} u_{d}-\frac{1}{L} v_{g d}-\dot{i}_{d, r e f}\right)+c_{2} e_{d}$.

By letting $\dot{S}_{d}=-k_{1} \operatorname{sgn}\left(S_{d}\right)$, the $d$ axis current control law is formulated in the following form:

$u_{d}=\frac{L}{v_{c}}\left(-\frac{k_{1}}{c_{1}} \operatorname{sgn}\left(S_{d}\right)-\frac{c_{2}}{c_{1}} e_{d}-\omega i_{q}+\frac{1}{L} v_{g d}+\dot{i}_{d, r e f}\right)$.

In Subsection 3.3 the $\mathrm{q}$ axis current controller is derived with details.

\subsection{Quadrature-axis current controller}

In Subsection 3.3 the $q$ axis current controller is derived and the stability proof is also presented. The $q$ axis current tracking error is defined as following:

$e_{q}=i_{q}-i_{q, r e f}$.

By taking the first derivative of Eq. (12), one obtains the following relation:

$\dot{e}_{q}=\dot{i}_{q}-\dot{i}_{q, r e f}$.

A proportional integral (PI) type sliding manifold and its first derivative is shown in Eq. (14):

$S_{q}=c_{3} e_{q}+c_{4} \int e_{q}$

$\dot{S}_{q}=c_{3} \dot{e}_{q}+c_{4} e_{q}$.

Substituting the dynamics of the q axis current from Eq. (1) into Eq. (13) and Eq. (14) yields the following expression:

$\dot{S}_{q}=c_{3}\left(-\omega i_{d}+\frac{1}{L} v_{c} u_{q}-\dot{i}_{q, r e f}\right)+c_{4} e_{q}$.

By letting $\dot{S}_{q}=-k_{2} \operatorname{sgn}\left(S_{q}\right)$, the $q$ axis current control law is formulated in the following form:

$u_{q}=\frac{L}{v_{c}}\left(-\frac{k_{2}}{c_{3}} \operatorname{sgn}\left(S_{q}\right)-\frac{c_{4}}{c_{3}} e_{q}+\omega i_{d}+i_{q, r e f}\right)$. 
The terms $c_{1}, c_{2}, c_{3}, c_{4}, c_{5}$ and $c_{6}$ represent the sliding manifold constants while $k_{1}, k_{2}$ and $k_{3}$ represent the discontinuous control gains.

\section{Numerical simulations, results and discussions}

Matlab/Simulink is used for performing the numerical simulations of the 3 phase grid tied inverter system with the derived controllers. The discontinuous control gains $k_{1}$, $k_{2}$ and $k_{3}$ are chosen as following: $k_{1}=61, k_{2}=1000$ and $k_{3}=1000$. The sliding manifold control gains $c_{1}, c_{2}, c_{3}, c_{4}, c_{5}$ and $c_{6}$ are tabulated in Table 1. The DC link capacitor is chosen as $C=470 \mu F$, filter inductance is set to $L=10 \mathrm{mH}$ with grid frequency $f=50 \mathrm{~Hz}$ and grid voltage $V_{g d}=220 \mathrm{~V}$. An active power load of $\frac{220 * 12}{\sqrt{2}}$ watts and maximum of 12 ampere is connected to the grid and the inverter system.

All other parameters are summarized in Table 1.

Two variants of controllers are tested. The performance of the proposed controller is compared with the smooth function based backstepping controllers. Two test cases are simulated with the details given in the cases referred as Test 1 and Test 2:

- Test 1: For test 1, the following reference commands are chosen: $v_{c}=500 \mathrm{~V}, Q_{r}=2200-3500 \mathrm{VAR}$. The simulation results obtained are shown as following. Figs. 3 and 4 show the active power tracking performance of the system under the action of two variants of the controllers. From Fig. 4, it is clear that the steady state error cannot be compensated by a saturation function based controller, while from Fig. 4 (a), the steady state error is very close to zero at time $t=2.57$. The reactive power simulation results are

Table 1 System and control parameters

\begin{tabular}{lc}
\hline Parameter & Value \\
\hline Grid frequency, $f$ & $50 \mathrm{~Hz}$ \\
Filter's Inductance, $L$ & $10 \mathrm{mH}$ \\
DC link capacitor, $C$ & $470 \mu \mathrm{F}$ \\
Grid voltage, $\mathrm{Vg} d$ & $220 \mathrm{~V}$ \\
$c_{1}$ & 1 \\
$c_{2}$ & 77.5 \\
$c_{3}$ & 1 \\
$c_{4}$ & 10 \\
$c_{5}$ & 1 \\
$c_{6}$ & 50 \\
$k_{1}$ & 61 \\
$k_{2}$ & 1000 \\
$k_{3}$ & 1000 \\
Boundary layer width & 0.1 \\
\hline
\end{tabular}

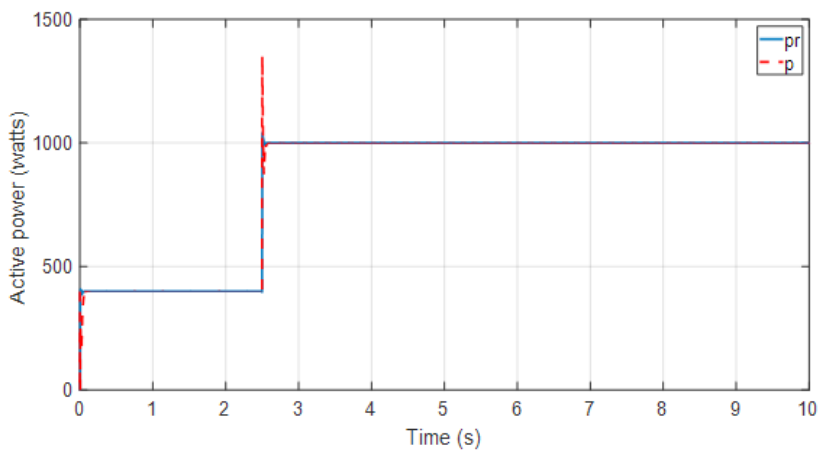

Fig. 3 Active power tracking

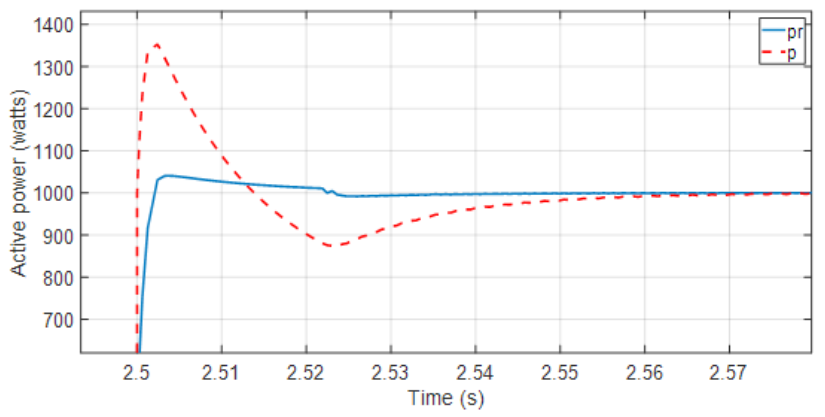

(a)

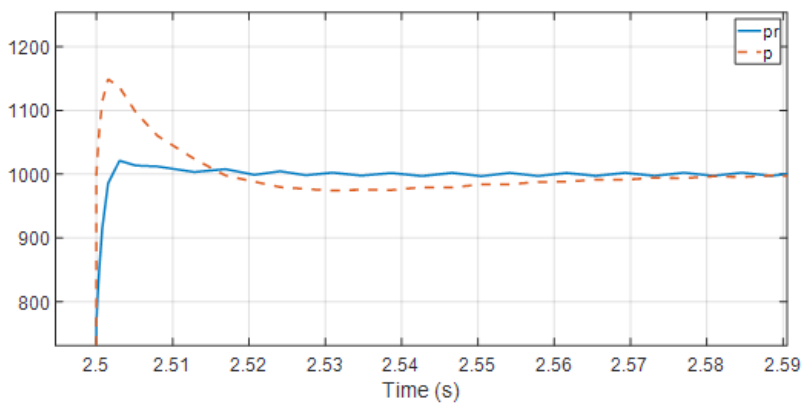

(b)

Fig. 4 Active power tracking (a) proposed control (b) proposed control with saturation function

shown in Fig. 5. From Fig 5 (b) it is very obvious that with the chosen reference commands, the steady state error in the reactive power loop is quite large with saturation function based control scheme while the proposed control scheme shows robust performance as evident from Fig. 5 (a). Figs. 6 (a) and (b) show the DC link voltage tracking response using the two variants of the grid tied inverter. It is obvious from the presented results that as we increase the width of the boundary layer, the steady error will tend to increase in the tracking signal. This fact is obvious from Fig. 6 (b). The variations in 3 phase currents and voltages are shown in Fig. 7 and Fig. 8. From the presented results it is clear that with the change in reference command of the active power, the three phase 


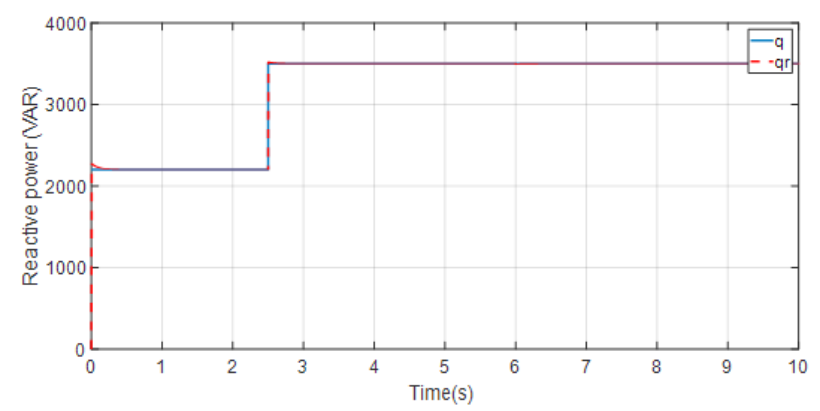

(a)

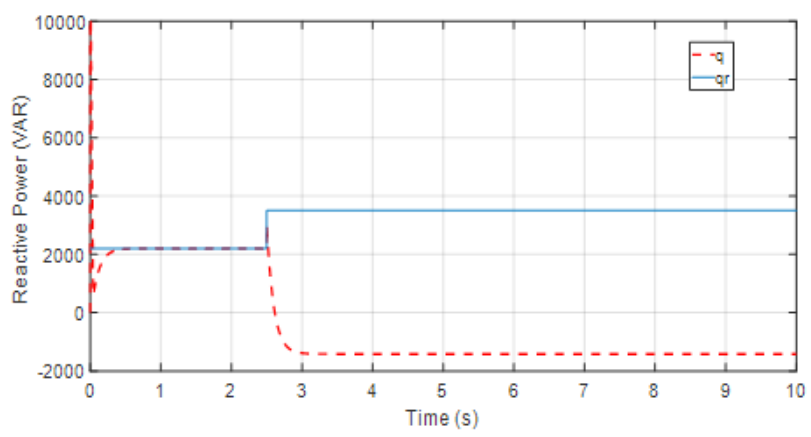

(b)

Fig. 5 Reactive power tracking (a) proposed control (b) proposed control with saturation function

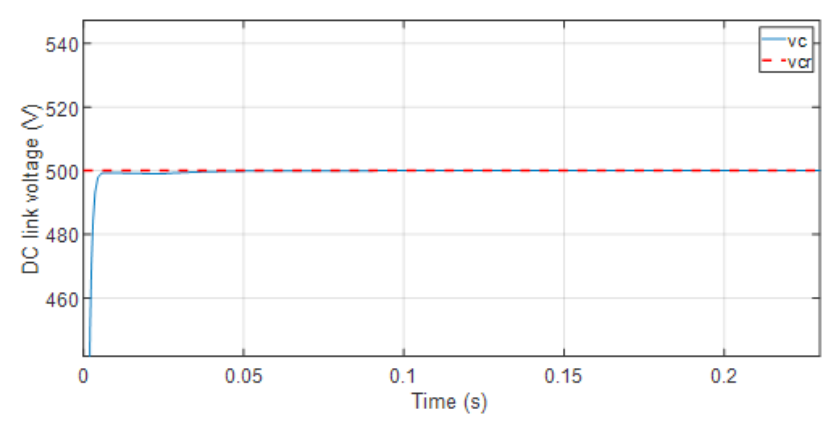

(a)

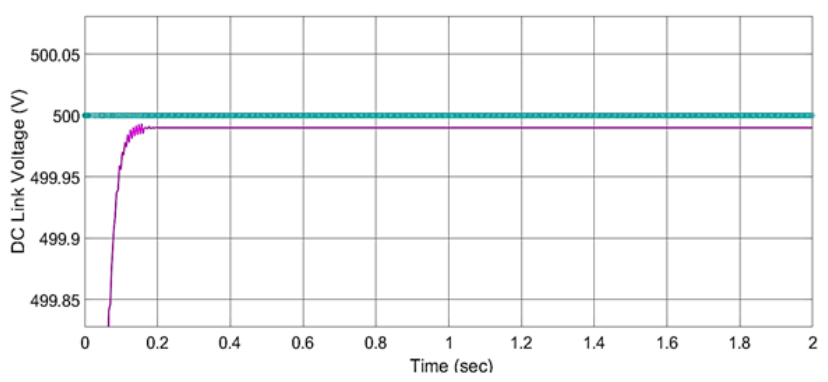

(b)

Fig. 6 DC link voltage tracking (a) proposed control (b) proposed control with saturation function

current flowing to the grid also increases from $5 \mathrm{~A}$ to $9 \mathrm{~A}$. However the 3 phase voltages remain almost constant. Fig. 9 shows the single phases of both the

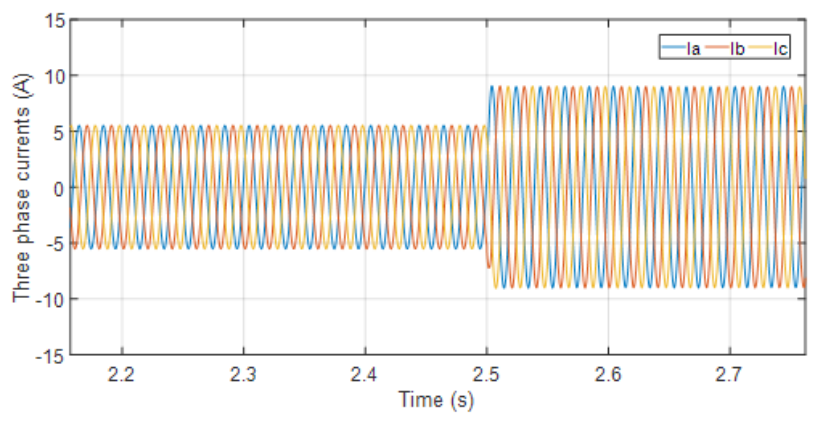

Fig. 73 phase current

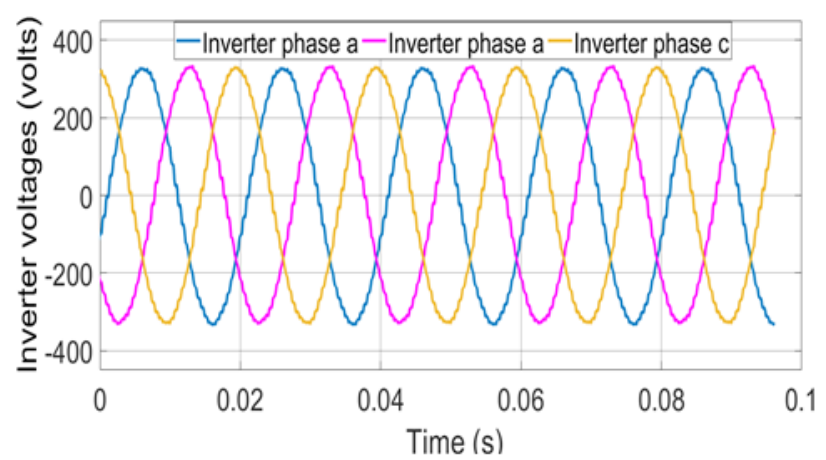

Fig. 83 phase voltages

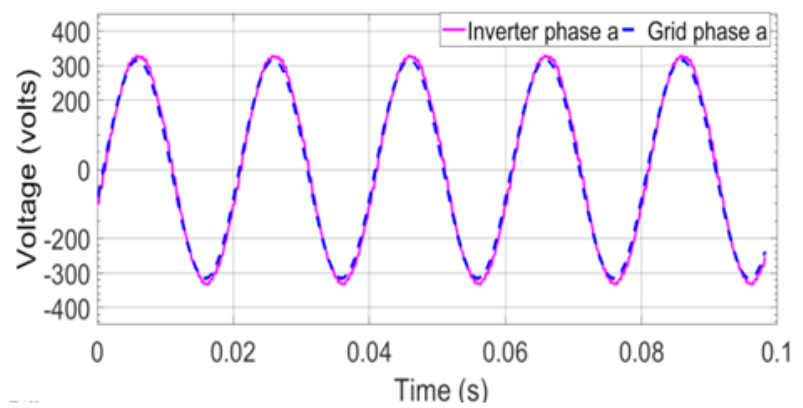

Fig. 9 Phase "a" comparison

grid and inverter voltages. It is clear that both the voltages are in phase and almost equal.

- Test 2: For test 2, the following reference commands are chosen:

$$
\begin{aligned}
& v_{c}=\left\{\begin{array}{l}
400 \mathrm{~V} \leq v_{c} \leq 500 \mathrm{~V}, 0 \leq t \leq 4 \\
500 \mathrm{~V}, 4 \leq t \leq 6 \\
500 \mathrm{~V}=v_{c} \leq 400 \mathrm{~V}, 4 \leq t \leq 10
\end{array}\right\}, \\
& Q_{r}=2200-3500 \mathrm{VAR} .
\end{aligned}
$$

The simulation results obtained are discussed below.

Figs. 10 (a) and (b) show the active power tracking with proposed control scheme. From Fig. 10 (b) it is clear that with the boundary layer design method, the settling time of the tracking signal is large as compared to the results presented in Fig. 10 (a). If the width of the boundary layer 


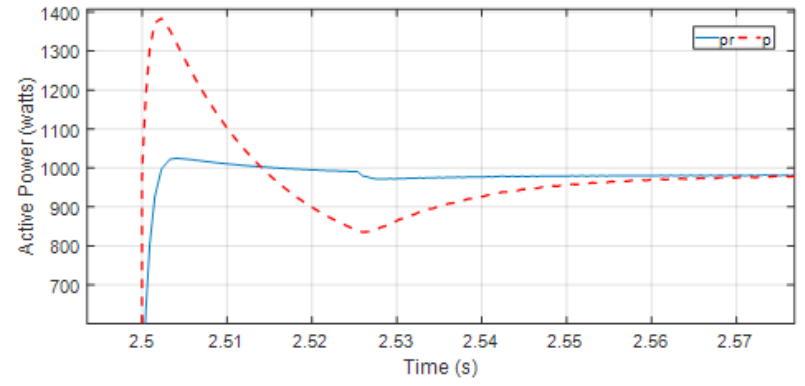

(a)

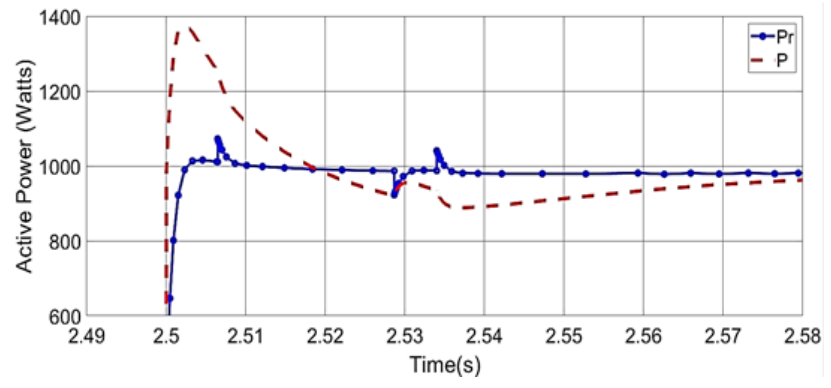

(b)

Fig. 10 Active power tracking (a) proposed control (b) proposed control with saturation function

is further increased, then the tracking response of the controller will become even worst and the steady state error will further increase.

Fig. 11 (a) and (b) show the reactive power tracking with the proposed control scheme and boundary layer controller respectively. As shown in Fig. 11 (b), with boundary layer method, the reactive power tracking suffers from a large overshoot and steady state error.

Fig. 12 (a) and (b) show DC link voltage tracking performance with the proposed control scheme and boundary layer controller respectively. As shown in Fig. 12 (b), with boundary layer method, the DC link voltage tracking suffers from a large steady state error. For Test 2, the variations in 3 phase currents is shown in Fig. 13. From the presented results it is clear that with the change in reference commands of the DC link voltage, the three phase current flowing to the grid also increases from $1 \mathrm{~A}$ to $2.5 \mathrm{~A}$.

\section{Conclusions}

This research proposes a variable structure control based back stepping approach for a 3 phase grid tied PV inverter. The proposed control scheme was implemented in the MATLAB/Simulink environment and its performance has been tested with several reference commands for active, reactive powers and DC link voltage. The proposed controller is compared with a saturation function based sliding mode controller. From the simulation results

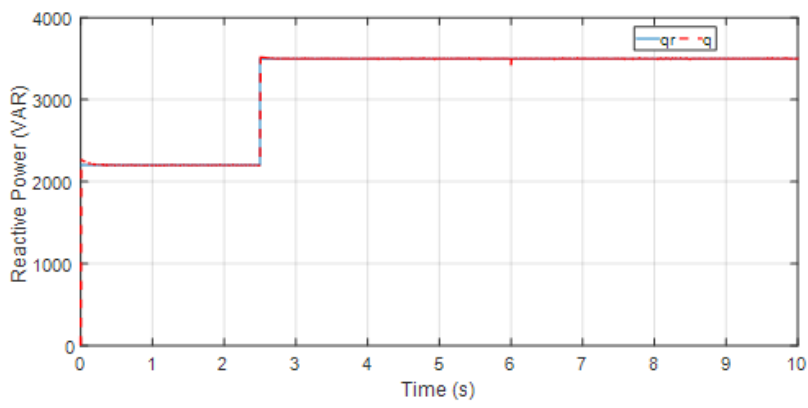

(a)

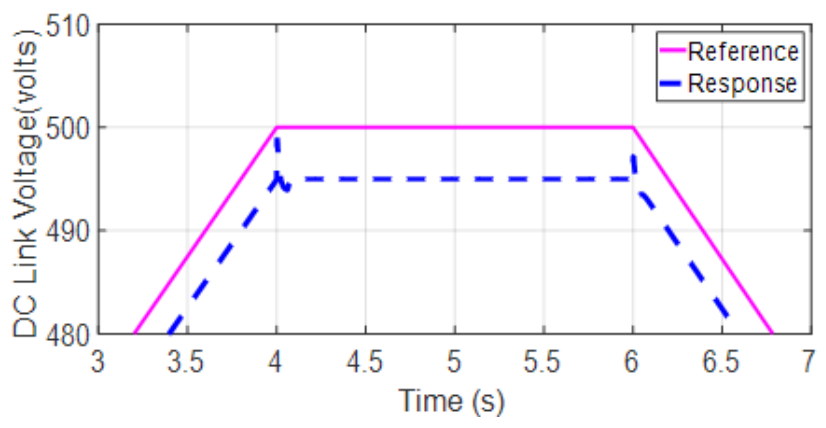

(b)

Fig. 11 Reactive power tracking (a) proposed control (b) proposed control with saturation function

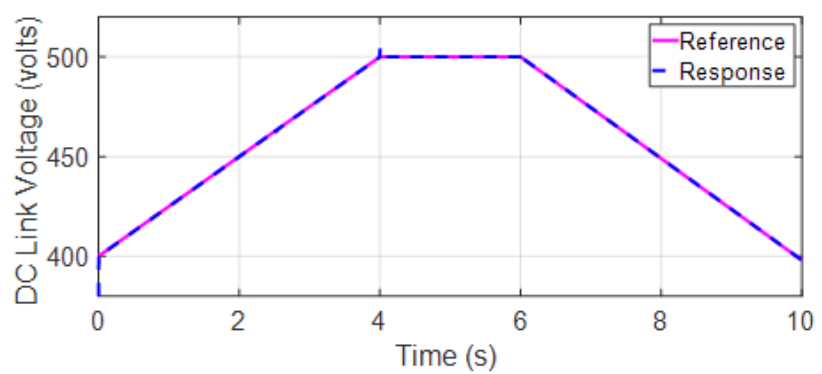

(a)

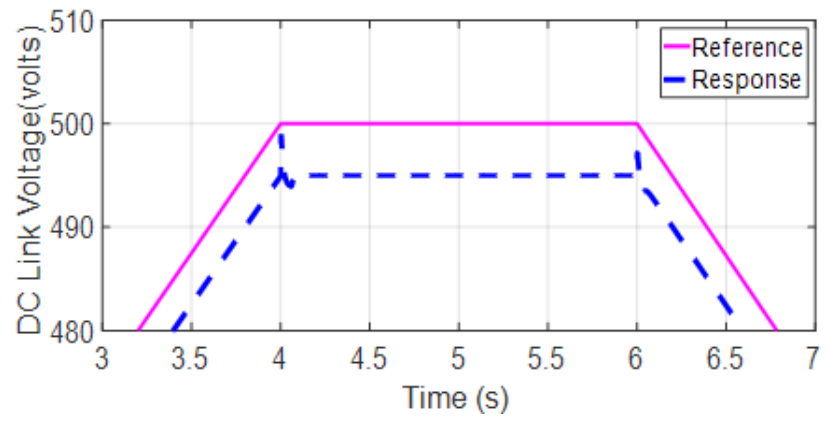

(b)

Fig. 12 DC link voltage tracking (a) proposed control (b) proposed control with saturation function

it is concluded that the proposed controller offers robust performance under all test conditions, while the saturation function based sliding mode control exhibits low chattering with a compromise on the robustness. 


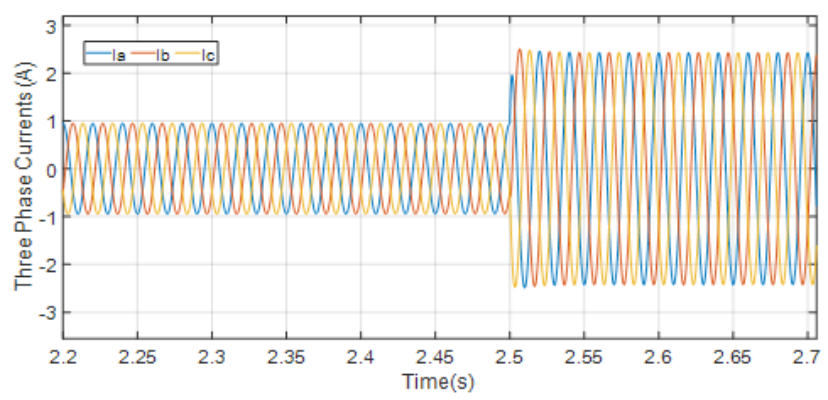

Fig. 133 Phase current

\section{References}

[1] Liu, L., Liu, R., Cao, Q., Chen, Q. "Design of a three-phase grid tied inverter", In: 2016 Chinese Control and Decision Conference (CCDC), Yinchuan, China, 2016, pp. 1246-1250. https://doi.org/10.1109/CCDC.2016.7531175

[2] Mechouma, R., Azoui, B., Chaabane, M. "Three-phase grid connected inverter for photovoltaic systems, a review", In: 2012 First International Conference on Renewable Energies and Vehicular Technology, Hammamet, Tunisia, 2012, pp. 37-42. https://doi.org/10.1109/REVET.2012.6195245

[3] Teodorescu, R., Liserre, M., Rodríguez, P. "Grid Converters for Photovoltaic and Wind Power Systems", John Wiley and Sons, Ltd., Chichester, UK, 2011.

https://doi.org/10.1002/9780470667057

[4] Al-Soud, M. S., Hrayshat, E. S. "Rural photovoltaic electrification program in Jordan", Renewable and Sustainable Energy Reviews, 8(6), pp. 593-598, 2004.

https://doi.org/10.1016/j.rser.2004.01.002

[5] Meral, M. E., Dinçer, F. "A review of the factors affecting operation and efficiency of photovoltaic based electricity generation systems", Renewable and Sustainable Energy Reviews, 15(5), pp. 2176-2184, 2011.

https://doi.org/10.1016/j.rser.2011.01.010

[6] López, Ó., Freijedo, F. D., Yepes, A. G., Fernández-Comesaña, P., Malvar, J., Teodorescu, R., Doval-Gandoy, J. "Eliminating Ground Current in a Transformerless Photovoltaic Application", IEEE Transactions on Energy Conversion, 25(1), pp. 140-147, 2010. https://doi.org/10.1109/TEC.2009.2037810

[7] Xiao, H., Xie, S. "Leakage Current Analytical Model and Application in Single-Phase Transformerless Photovoltaic GridConnected Inverter", IEEE Transactions on Electromagnetic Compatibility, 52(4), pp. 902-913, 2010.

https://doi.org/10.1109/TEMC.2010.2064169

[8] Barater, D., Buticchi, G., Lorenzani, E., Concari, C. "Active Common-Mode Filter for Ground Leakage Current Reduction in Grid-Connected PV Converters Operating with Arbitrary Power Factor", IEEE Transactions on Industrial Electronics., 61(8), pp. 3940-3950, 2014.

https://doi.org/10.1109/TIE.2013.2284160

[9] Buticchi, G., Barater, D., Lorenzani, E., Franceschini, G. "Digital Control of Actual Grid-Connected Converters for Ground Leakage Current Reduction in PV Transformerless Systems", IEEE Transactions on Industrial Informatics, 8(3), pp. 563-572, 2012. https://doi.org/10.1109/TII.2012.2192284
[10] Gonzalez, R., Lopez, J., Sanchis, P., Marroyo, L. "Transformerless Inverter for Single-Phase Photovoltaic Systems", IEEE Transactions on Power Electronics, 22(2), pp. 693-697, 2007. https://doi.org/10.1109/TPEL.2007.892120

[11] Khan, M. N. H., Ahmad, K. J., Khan, S., Hasanuzzaman, M. "Leakage Current Paths in PV Transformer-Less Single-Phase Inverter Topology and Its Mitigation through PWM for Switching", International Journal of Power Electronics and Drive System (IJPEDS), 6(1), pp. 148-159, 2015. [online] Available at: http://ijpeds.iaescore.com/index.php/IJPEDS/article/download/5111/4561 [Accessed: 10 December 2019]

[12] Souza Figueredo, R., Mingorancia De Carvalho, K. C., Ama, N. R. N., Matakas, L. "Leakage current minimization techniques for single-phase transformerless grid-connected PV inverters - An overview", In: 2013 Brazilian Power Electronics Conference, Gramado, Brazil, 2013, pp. 517-524. https://doi.org/10.1109/COBEP.2013.6785164

[13] Zografos, D., Koutroulis, E., Yang, Y., Blaabjerg, F. "Minimization of leakage ground current in transformerless single-phase fullbridge photovoltaic inverters", In: 2015 17th European Conference on Power Electronics and Applications (EPE'15 ECCE-Europe), Geneva, Switzerland, 2015, pp. 1-10. https://doi.org/10.1109/EPE.2015.7309232

[14] Khan, M. N. H., Forouzesh, M., Siwakoti, Y. P., Li, L., Kerekes, T., Blaabjerg, F. "Transformerless Inverter Topologies for SinglePhase Photovoltaic Systems: A Comparative Review", IEEE Journal of Emerging and Selected Topics in Power Electronics, 8(1), pp. 805-835, 2020. https://doi.org/10.1109/JESTPE.2019.2908672

[15] Patrao, I., Figueres, E., González-Espín, F., Garcerá, G. "Transformerless topologies for grid-connected single-phase photovoltaic inverters", Renewable and Sustainable Energy Reviews, 15(7), pp. 3423-3431, 2011. https://doi.org/10.1016/j.rser.2011.03.034

[16] Selvaraj, J., Rahim, N. A., Krismadinata, C. "Digital PI current control for grid connected PV inverter", In: 2008 3rd IEEE Conference on Industrial Electronics and Applications, Singapore, Singapore, 2008, pp. 742-746. https://doi.org/10.1109/ICIEA.2008.4582614

[17] Arzani, A., Arunagirinathan, P., Venayagamoorthy, G. K. "Development of Optimal PI Controllers for a Grid-Tied Photovoltaic Inverter", In: 2015 IEEE Symposium Series on Computational Intelligence, Cape Town, South Africa, 2015, pp. 1272-1279. https://doi.org/10.1109/SSCI.2015.182 
[18] Karbakhsh, F., Gharehpetian, G. B., Milimonfared, J., Teymoori, A. "Three phase photovoltaic grid-tied inverter based on feed-forward decoupling control using fuzzy-PI controller", In: 2016 7th Power Electronics and Drive Systems Technologies Conference (PEDSTC), Tehran, Iran, 2016, pp. 344-348. https://doi.org/10.1109/PEDSTC.2016.7556885

[19] Lin, F. J., Lu, K. C., Ke, T. H., Yang, B. H., Chang, Y. R. "Reactive Power Control of Three-Phase Grid-Connected PV System During Grid Faults Using Takagi-Sugeno-Kang Probabilistic Fuzzy Neural Network Control", IEEE Transactions on Industrial Electronics, 62(9) , pp. 5516-5528, 2015. https://doi.org/10.1109/TIE.2015.2407851

[20] Lakshmi, T. L., Naik, M. G. "Control of Novel PV Inverter with ANFIS in Grid Tied PV System Under Unbalanced Grid Condition", In: 2018 2nd International Conference on Trends in Electronics and Informatics (ICOEI), Tirunelveli, India, 2018, pp. 564-569. https://doi.org/10.1109/ICOEI.2018.8553749

[21] Ebrahimpanah, S., Chen, Q., Zhang, L. "Model Predictive Current Control with Duty Cycle Optimization for Two-Level Three-Phase Grid-Tied Inverter with Output LCL Filter Based on Forward Euler Approximation", In: 2017 International Conference on Industrial Informatics - Computing Technology, Intelligent Technology, Industrial Information Integration (ICIICII), Wuhan, China, 2017, pp. 155-158.

https://doi.org/10.1109/ICIICII.2017.51

[22] Geldenhuys, J. M. C., du Toit Mouton, H., Rix, A., Geyer, T. "Model predictive current control of a grid connected converter with LCLfilter", In: 2016 IEEE 17th Workshop on Control and Modeling for Power Electronics (COMPEL), Trondheim, Norway, 2016, pp. 1-6. https://doi.org/10.1109/COMPEL.2016.7556734
[23] Trabelsi, M., Bayhan, S., Refaat, S. S., Abu-Rub, H., Ben-Brahim, L. "Multi-objective model predictive control for grid-tied 15-level packed U cells inverter", In: 2016 18th European Conference on Power Electronics and Applications (EPE'16 ECCE Europe), Karlsruhe, Germany, 2016, pp. 1-7. https://doi.org/10.1109/EPE.2016.7695327

[24] Ullah, N., Wang, S. P. "Backstepping Control of Electrical Load Simulator with Adaptive Tracking Performance Controller", Applied Mechanics and Materials, 245, 2012, pp. 310-315. https://doi.org/10.4028/www.scientific.net/AMM.245.310

[25] Ullah, N., Asghar, M., Khattak, A., Rafiq, M. M. "Comparison of integer and fractional order robust controllers for DC/DC converter feeding constant power load in a DC microgrid", Sustainable Energy, Grids and Networks, 12, 2017, pp. 1-9. https://doi.org/10.1016/j.segan.2017.08.003

[26] Ahmad, A., Ullah, N., Ahmed, N., Ibeas, A, Mehdi, G., Herrera, J., Ali, A. "Robust Control of Grid-Tied Parallel Inverters Using Nonlinear Backstepping Approach", IEEE Access, 7, 2019, pp. 111982-111992. https://doi.org/10.1109/ACCESS.2018.2875030

[27] Altin, N., Ozdemir, S., Komurcugil, H., Sefa, I. "Sliding-Mode Control in Natural Frame with Reduced Number of Sensors for Three-Phase Grid-Tied LCL-Interfaced Inverters", IEEE Transactions on Industrial Electronics, 66(4), pp. 2903-2913, 2019. https://doi.org/10.1109/TIE.2018.2847675

[28] Bagheri, F., Komurcugil, H., Kukrer, O. "Fixed switching frequency sliding-mode control methodology for single-phase LCLfiltered quasi-Z-source grid-tied inverters", In: 2018 IEEE 12th International Conference on Compatibility, Power Electronics and Power Engineering (CPE-POWERENG 2018), Doha, Qatar, 2018, pp. 1-6.

https://oi.org/10.1109/CPE.2018.8372518 